\title{
BMJ Open Socioeconomic status and geographical factors associated with active listing in primary care: a cross-sectional population study accounting for multimorbidity, age, sex and primary care
}

Karin Ranstad, ${ }^{1,2}$ Patrik Midlöv, ${ }^{1}$ Anders Halling ${ }^{1}$

To cite: Ranstad K, Midlöv P, Halling A. Socioeconomic status and geographical factors associated with active listing in primary care: a cross-sectional population study accounting for multimorbidity, age, sex and primary care. BMJ Open 2017;7:e014984. doi:10.1136/ bmjopen-2016-014984

Received 31 October 2016 Revised 13 March 2017 Accepted 15 March 2017
CrossMark

${ }^{1}$ Department of Clinical Sciences in Malmö, Center for Primary Health Care Research, Lund University, Lund, Sweden ${ }^{2}$ Nättraby Primary Health Care Centre, Nättraby, Sweden

\section{Correspondence to} Dr. Karin Ranstad; karin.ranstad@med.lu.se, karin. ranstad@Itblekinge.se

\section{ABSTRACT}

Background Socioeconomic status and geographical factors are associated with health and use of healthcare. Well-performing primary care contributes to better health and more adequate healthcare. In a primary care system based on patient's choice of practice, this choice (listing) is a key to understand the system.

Objective To explore the relationship between population and practices in a primary care system based on listing. Methods Cross-sectional population-based study. Logistic regressions of the associations between active listing in primary care, income, education, distances to healthcare and geographical location, adjusting for multimorbidity, age, sex and type of primary care practice.

Setting and subjects Population over 15 years $(\mathrm{n}=123168)$ in a Swedish county, Blekinge (151 731 inhabitants), in year 2007, actively or passively listed in primary care. The proportion of actively listed was $68 \%$. Main outcome measure Actively listed in primary care on 31 December 2007.

Results Highest ORs for active listing in the model including all factors according to income had quartile two and three with $\mathrm{OR} 0.70$ (95\% $\mathrm{Cl} 0.69$ to 0.70 ), and those according to education less than 9 years of education had OR 0.70 (95\% Cl 0.68 to 0.70). Best odds for geographical factors in the same model had municipality $\mathrm{C}$ with $\mathrm{OR}$ $0.85(95 \% \mathrm{Cl} 0.85$ to 0.86$)$ for active listing. Akaike's Information Criterion (AIC) was 124801 for a model including municipality, multimorbidity, age, sex and type of practice and including all factors gave AIC 123934.

Conclusions Higher income, shorter education, shorter distance to primary care or longer distance to hospital is associated with active listing in primary care. Multimorbidity, age, geographical location and type of primary care practice are more important to active listing in primary care than socioeconomic status and distance to healthcare.

\section{INTRODUCTION}

Importance of primary care increases as healthcare focuses more on complex health
Strengths and limitations of this study

- Cross-sectional study combining individual factors from different data sources for the population of a small Swedish county ( $\mathrm{N}=151731$ inhabitants).

- The study county had a relatively simply organised healthcare system and a listing system comparable to contemporary Swedish primary care.

- Active listing, reflecting the relationship between patients and primary care practices, underestimated this relationship since passive listing at the practice of choice would be sufficient.

- It was within the aim of this paper to investigate associations with active listing according to studied factors, not causality.

problems than on single diagnoses. Good relations between individuals in a population and well-performing primary care contribute to better health and a healthcare system that is more adequate. ${ }^{12}$ Patient satisfaction and attachment to primary care affect the choice of primary care practices. ${ }^{3-7}$

To patients, active listing is a complex choice, ${ }^{8}$ linked to trust. In the theory on social capital, trust is a key factor at the individual level. ${ }^{9}$ Low levels of trust and social participation are positively associated with lack of belief in the possibility to influence one's own health. ${ }^{10}$ When analysing self-reported lack of access to a regular doctor, it is suggested that both healthcare district and social capital contribute to the perceived lack of access. ${ }^{3}$ Individuals with low institutional trust in the healthcare system have poor self-perceived health that might be partly mediated by careseeking behaviour. ${ }^{11}$ Both multimorbidity and trust are connected to socioeconomic status and geographical factors. ${ }^{11-13}$ 
In Sweden, primary care practices composed of general practitioners (GPs) organised within multidisciplinary teams. ${ }^{14}$ County councils finance and regulate local healthcare, organising primary care into quasi-market models, which have been mandatory since $2010 .{ }^{15}{ }^{16} \mathrm{In}$ 2004, the County of Blekinge introduced listing (choice of practice) in primary care. Listing was mandatory passive or active, and the choice between them was owned by the individual. Patients initiated active listing by notifying any practice within the county. Access and availability to primary care were the same despite listing status. Active listing could be associated with the relationship between patients and their primary care practice. This listing system was generalisable within a Swedish context ${ }^{1417}$ and was comparable with other primary care systems allowing active listing.

The combined associations between active listing, multimorbidity, socioeconomic status and geographical factors have not been assessed before in a European population. Our aim was to explore the relation between population and practices in a primary care system based on listing by describing the associations between active listing, socioeconomics and geography, adjusting for multimorbidity, age, sex and type of primary care practice.

\section{Materials and methods}

\section{Study population and design}

Year 2007 represents a period without major structural or political changes, with stability in regulations, funding and workforce settings in primary care in Blekinge. On 31 December 2007, the County of Blekinge had 151380 inhabitants. Of these, $50.5 \%$ were men and the average age was 42.7 years. ${ }^{18}$ Healthcare was provided by two hospitals, five psychiatric clinics and 25 primary care practices. Half of the primary care practices were owned privately, established in all municipalities.

Listing in primary care was introduced in 2004 to empower patients, introduce market economy principles and distribute funding to practices. Active or passive listing was the only listing options. The practice of choice administrated active listing. Fundings and regulations were the same for actively and passively listed and for all practices. A total of $65 \%$ inhabitants were actively listed, ranging between $50 \%$ and $85 \%$ according to municipality. The majority $(84 \%)$ were listed in practices owned by the county council, mostly at the nearest primary care practice.

We collected data on diagnoses used for estimating multimorbidity level and listing status from electronic patient records and other factors from Statistics Sweden. ${ }^{19}$ Socioeconomic data were missing for individuals $<16$ years of age (24 741), and information on educational level or residence was missing for 3471 individuals $>15$ years of age. This cross-sectional population-based study was restricted to the 123168 individuals with no missing data. This population had an average age of 50.1 years, $50.2 \%$ were men and 83738 (68\%) were actively listed.
The Regional Ethical Review Board at Lund University (application no. 2010/314) approved the study.

\section{Conceptual model}

Socioeconomic and geographical factors affect individual health, availability and demand for healthcare, along with multimorbidity. Primary care is a substantial part of ambulatory care. Listing is a key to the system in primary care based on patient's choice of provider. Listing status could measure aspects of the relation between primary care and the population other than number of contacts. Active listing could be seen as patients acting to promote and stress their relationship with primary care, as long as care is available to all and nothing obvious is gained by active listing instead of passive.

\section{Outcome}

Actively listed in primary care on 31 December 2007.

Listing was mandatory passive at the nearest primary care practice. Active or passive listing was the only options. Patients could change listing to active at will, at the same practice or another within the county, by notifying the practice of choice. Family members over 15 years of age made their choices individually. Access and availability to primary care were the same regardless of listing status. Patients or practices gained no obvious favours from primary care by active instead of passive listing. Passively listed were relisted if they moved to another municipality or if a new primary care practice became the nearest. Primary care practices were obliged to accept any patient and to distribute care according to medical need.

\section{Explanatory factors}

Disposable income in four equally numbered groups (quartiles)

Income at disposal is net income, adjusted for taxation and subsidiaries.

Education was divided into four levels: (1) less than 9 years of education, (2) completed 9 years of compulsory education, (3) college degree or (4) university degree. Of the study population, $13 \%$ had completed 9 years of education, $44.4 \%$ had a college degree and $25.1 \%$ had a degree from university.

Distance in kilometres $(\mathrm{km})$ from home to nearest primary care practice, in seven levels $(0-1,>1-5,>5-10$, $>10-15,>15-20,>20-25$ and $>25)$, was measured as the shortest distance between two points.

Distance in kilometres $(\mathrm{km})$ from home to nearest hospital, in six levels $(0-5,>5-10,>10-15,>15-20,>20-25$ and $>25$ ), was measured as described above.

Geographical location were five municipalities (local government areas). The population in municipality $\mathrm{A}$ was $41 \%$, in $\mathrm{B}$ was $19 \%$, in $\mathrm{C}$ was $21 \%$, in $\mathrm{D}$ was $11 \%$ and in $\mathrm{E}$ was $9 \%$ of the total population. Hospitals were located in municipalities A and C. Private primary care was available in every municipality.

Multimorbidity level was calculated from patient records from all healthcare for 2007 using the Johns Hopkins Adjusted Clinical Groups Case Mix System (ACG). This 
is one of the summary measures aiming to link diagnoses with their impact on consumption of healthcare. These measures are focused on stratification or classification of patients into groups according to diseases and conditions, age and sex. ACG weights patients' diagnoses according to five clinical dimensions: duration, severity, diagnostic certainty, aetiology and need for specialist care. That index is then categorised into multimorbidity levels with similar impact on consumption of healthcare called Resource Utilization Bands (RUBs) ranging from 0 (no need for healthcare) to 5 (very strong need for healthcare).$^{2021}$

Age and sex were age grouped in 16-19, 20-39, 40-59, 60-79 and 80 years and above.

Type of primary care practice was categorised in two groups according to ownership that also included differences in size and time since establishment. The county council contracted all primary care practices. This gave equal funding and regulations but different settings and processes among primary care practices. Public practices were typically older, with more listed patients and GPs, than private practices. Of patients listed in private primary care, $60 \%$ had little or no need for healthcare, compared with $35 \%$ in public primary care; income and education were equally distributed. A few older private practices used an option not to have passively listed.

\section{Statistical analysis}

Statistical analyses were performed with STATA V.14.1 (Stata). We used pairwise correlations, univariate and multivariate logistic regression models and several methods to test our models. Akaike's Information Criterion (AIC) has a penalty term for additional parameters; lower values were preferred. Coefficient of variance (CV) standardises SD, using absolute mean, to allow for comparison of variance across models. Likelihood ratio statistics (LR test) tested differences between nested models. Higher values indicate greater difference from the simpler model than low values. Model performance was also assessed using c-statistics (area under the curve (AUC)), equivalent to the area under the receiver operating characteristics (ROC) curve, with one indicating perfect discrimination and 0.5 equal to chance.

\section{RESULTS}

Pairwise correlations showed correlation between active listing and multimorbidity $(0.30)$, age $(0.27)$ and municipality (0.21). Income and education were correlated $(0.35)$. Income was also correlated with sex (0.23). Education level also correlated with age $(-0.31)$. Distances to primary care and hospital were correlated (0.36). Municipality was also correlated with practice type $(-0.25)$ and distance to hospital (0.44).

The share of actively listed ranged from $63 \%$ to $77 \%$ according to income and ranged from 59\% to $83 \%$ according to education. According to distance to primary care, active listing ranged from $63 \%$ to $69 \%$, and that according to distance to hospital ranged from $62 \%$ to $72 \%$. Active listing ranged from $55 \%$ to $85 \%$ according to geographical location (table 1 ).

In univariate models, all factors were significantly $(p<0.01)$ associated with active listing, but variance and model fit differed. CV was 8.1 for income, 11.8 for education, 1.6 for distance to primary care, 4.3 for distance to hospital and 17.8 for municipality (table 2 ).

\section{Multivariate models}

Both unadjusted and adjusted multivariate models showed significance $(\mathrm{p}<0.01)$ for socioeconomic and geographical factors (table 3). The model including all socioeconomic and geographical factors, adjusting for multimorbidity, age, sex and type of practice, gave the lowest odds of active listing according to income for those in the first quartile with OR 0.63 (95\% CI 0.63 to 0.64$)$ and highest for those in quartile two or three with OR 0.70 (95\% CI 0.69 to 0.70$)$. According to educational level, this model gave those with less than 9 years of education OR $0.70(95 \%$ CI 068 to 0.70$)$ and those with university degree OR 0.65 (95\% CI 0.64 to 0.65 ) for active listing. A distance to primary care of $>15-20 \mathrm{~km}$ gave OR $0.62(0.60$ to 0.65$)$ and that of $1 \mathrm{~km}$ or less gave OR 0.69 (95\% CI 0.69 to 0.70 ) of active listing. For distance to hospital $>5-10 \mathrm{~km}$ gave OR 0.64 (95\% CI 0.64 to 0.65$)$ and more than $25 \mathrm{~km}$ gave OR 0.71 (95\% CI 0.70 to 0.73 ). ORs according to geographic location for active listing ranged from 0.58 (95\% CI 0.57 to 0.58 ) in municipality A to 0.85 ( $95 \%$ CI 0.85 to 0.86 ) in municipality C (table 4 ).

\section{Model tests}

AIC for the model with age and sex was 143 382, including multimorbidity, practice type gave AIC 133 429, and including municipality to that model gave AIC 124801 (table 4). The model including all socioeconomic and geographical factors and adjusting for multimorbidity, age, sex and type of practice gave AIC 123934 (table 4).

CV for a model including multimorbidity, age and sex was 26.0 and that including municipality, multimorbidity, age and sex was 32.2 (table 3). Including income, education or distances to healthcare to this model gave at most CV 32.4, including type of practice CV 32.7 (table 3). The model including all socioeconomic and geographical factors and adjusting for multimorbidity, age, sex and type of practice gave CV 33.2 (table 3).

We tested nested models using LR tests. Adding municipality, multimorbidity or practice type added most difference to a model with age and sex (table 3). Adding socioeconomic factors or distances to healthcare to the model including municipality, multimorbidity, age and sex gave LR tests ranging from 123 for adding distance to primary care to 359 for adding individual income (table 3).

Model performance was also tested using c-statistics. Univariate models on municipality, multimorbidity level, age and type of practice gave AUC $>0.6$ (table 2). Age and sex gave a model with AUC 0.679 (95\% CI 0.676 to 0.682 ). 
Table 1 Descriptive: unadjusted for the population of Blekinge $2007>15$ years, with no missing data $(n=123168)$

\begin{tabular}{lll}
\hline & Group size & Actively listed \\
\cline { 2 - 3 } Descriptive & $\mathbf{N}(\%)$ & $\mathbf{N}(\%)$ \\
\hline
\end{tabular}

\begin{tabular}{|c|c|c|}
\hline \multicolumn{3}{|c|}{ Individual income } \\
\hline $1 / 4$ & 29588 (24.0) & 18843 (63.7) \\
\hline $2 / 4$ & 30933 (25.1) & 23764 (76.8) \\
\hline $3 / 4$ & 31339 (25.4) & 21415 (68.3) \\
\hline $4 / 4$ & 31308 (25.4) & $19716(63.0)$ \\
\hline
\end{tabular}

Educational level

\begin{tabular}{|c|c|c|}
\hline Less than 9 years & 21602 (17.5) & $18034(83.5)$ \\
\hline 9 years & 15956 (13.0) & $10128(63.5)$ \\
\hline College degree & $54693(44.4)$ & $37319(68.2)$ \\
\hline University degree & $30917(25.1)$ & $18257(59.0)$ \\
\hline \multicolumn{3}{|l|}{ Distance primary care } \\
\hline $0-1 \mathrm{~km}$ & $53885(43.7)$ & $37044(68.7)$ \\
\hline$>1-5 \mathrm{~km}$ & 40669 (33.0) & $27268(67.0)$ \\
\hline$>5-10 \mathrm{~km}$ & $21374(17.3)$ & $14704(68.8)$ \\
\hline$>10-15 \mathrm{~km}$ & $5088(4.1)$ & $3370(66.2)$ \\
\hline$>15-20 \mathrm{~km}$ & $1852(1.5)$ & $1164(62.8)$ \\
\hline$>20 \mathrm{~km}$ & $300(0.2)$ & $188(62.7)$ \\
\hline \multicolumn{3}{|l|}{ Distance hospital } \\
\hline $0-5 \mathrm{~km}$ & 45378 (36.8) & $30514(67.2)$ \\
\hline$>5-10 \mathrm{~km}$ & 14659 (11.9) & $9786(66.8)$ \\
\hline$>10-15 \mathrm{~km}$ & $11689(9.5)$ & 7267 (62.2) \\
\hline$>15-20 \mathrm{~km}$ & $15911(12.9)$ & $10850(68.2)$ \\
\hline$>20-25 \mathrm{~km}$ & 31141 (25.3) & $22492(72.2)$ \\
\hline$>25 \mathrm{~km}$ & 4390 (3.6) & $2829(64.4)$ \\
\hline \multicolumn{3}{|l|}{ Municipality } \\
\hline A & $49931(40.5)$ & $27700(55.5)$ \\
\hline B & 23286 (18.9) & $15297(65.7)$ \\
\hline C & 25405 (20.6) & $21723(85.5)$ \\
\hline D & $13697(11.1)$ & $10924(79.5)$ \\
\hline E & $10849(8.8)$ & 8094 (74.6) \\
\hline \multicolumn{3}{|l|}{ Multimorbidity level } \\
\hline RUB 0 & $48211(39.1)$ & $25030(51.9)$ \\
\hline RUB 1 & 15315 (12.4) & $10391(67.8)$ \\
\hline RUB 2 & $25242(20.5)$ & $18861(74.7)$ \\
\hline RUB 3 & 30566 (24.8) & $25983(85.0)$ \\
\hline RUB 4 & $3233(2.6)$ & 2909 (90.0) \\
\hline RUB 5 & $601(0.5)$ & $564(93.8)$ \\
\hline \multicolumn{3}{|l|}{ Age } \\
\hline 16-19years & $6846(5.6)$ & 3777 (55.2) \\
\hline 20-39years & $34067(27.7)$ & $17904(52.6)$ \\
\hline 40-59years & 39374 (32.0) & $26176(66.5)$ \\
\hline $60-79$ years & $33420(27.1)$ & $27386(81.9)$ \\
\hline $80+$ years & $9461(7.7)$ & 8495 (89.8) \\
\hline
\end{tabular}

Continued
Table 1 Continued

\begin{tabular}{lcl}
\hline \multirow{2}{*}{ Descriptive } & Group size & Actively listed \\
\cline { 2 - 3 } & N (\%) & N (\%) \\
\hline Sex & & \\
$\quad$ Women & $61386(49.8)$ & $45004(73.3)$ \\
$\quad$ Men & $61782(50.2)$ & $38734(62.7)$ \\
$\quad$ Practice type & & \\
$\quad$ Private & $20428(16.6)$ & $15798(77.3)$ \\
$\quad$ Public & $102740(83.4)$ & $67940(66.1)$ \\
Population of Blekinge & 123168 & $83738(68.0)$ \\
\hline
\end{tabular}

Unadjusted actively listed 2007 distributed on subgroups of each explanatory factor for the population of Blekinge $>15$ years of age. RUB, Resource Utilization Band.

Modelling multimorbidity, age, sex and type of practice gave AUC 0.747 (95\% CI 0.744 to 0.750 ) and including municipality to that model gave AUC 0.788 (95\% CI 0.785 to 0.790 ) (table 3). The model including all factors gave AUC 0.792 (95\% CI 0.789 to 0.795$)$ (table 4 ).

\section{Comparing multivariate logistic models}

When modelling all factors for the population of Blekinge, those with incomes in the third quartile showed $49 \%$ (95\% CI $42 \%$ to $55 \%$ ) more actively listed than those in the lowest quartile. Of those with a university degree, $26 \%$ (95\% CI $22 \%$ to $30 \%$ ) less were actively listed than those without completed 9 years compulsory school. OR for active listing in municipality $\mathrm{C}$ was 5.62 (95\% CI 5.37 to 5.87) times the OR in municipality A. OR for active listing increased with multimorbidity level to 9.27 (95\% CI 6.60 to 13.02) for RUB 5 compared with RUB 0 . The association between age group and active listing was not linear. Men had OR 0.68 (95\% CI 0.66 to 0.70 ) compared with women. Public practices had OR 0.53 (95\% CI 0.51 to 0.55 ) compared with private practices (table 5).

The logistic model for the subpopulation of municipality A showed OR for the second income quartile 1.45 (95\% CI 1.36 to 1.55 ) compared with the first quartile. University degree had OR 0.77 (95\% CI 0.71 to 0.84 ) compared with those without completed 9 years compulsory school (table 5 ).

The model for the subpopulation of municipality $\mathrm{C}$ showed OR 1.87 (95\% CI 1.66 to 2.11) for third income quartile compared with first quartile. University degree had OR 0.66 (95\% CI 0.56 to 0.79 ) compared with those without completed 9 years compulsory school (table 4 ).

\section{DISCUSSION}

\section{Summary of main findings}

Higher income, shorter education, short distance to primary care and long distance to hospital had a significant association with active listing in primary care.

Multimorbidity, age, geographical location and primary care explain more of the differences in active listing than socioeconomic status and distance to healthcare. 
Table 2 Univariate models: active listing in primary care according to multimorbidity, income, education, distances to healthcare, age, sex, practice type and geographical location for the population of Blekinge 2007 aged $>15$ years, with no missing data $(n=123168)$

\begin{tabular}{llcc}
\hline & Area under ROC Curve & CV & AIC \\
\cline { 2 - 4 } Univariate models & AUC $(\mathbf{9 5 \%}$ Cl) & $\%$ & 152676 \\
\hline Individual income & $0.567(0.563$ to 0.570$)$ & 11.8 & 150534 \\
Educational level & $0.596(0.592$ to 0.599$)$ & 1.6 & 154387 \\
Distance primary care & $0.512(0.509$ to 0.515$)$ & 4.3 & 153970 \\
Distance hospital & $0.535(0.532$ to 0.539$)$ & 17.8 & 145699 \\
Municipality & $0.653(0.650$ to 0.656$)$ & 20.7 & 142772 \\
Multimorbidity level & $0.678(0.675$ to 0.681$)$ & 18.9 & 144592 \\
Age & $0.663(0.660$ to 0.666$)$ & 11.5 & 152848 \\
Sex & $0.561(0.558$ to 0.564$)$ & 21.0 & 142320 \\
\hline Practice type & $0.687(0.684$ to 0.691$)$ & & \\
\hline
\end{tabular}

$\mathrm{n}=123168$ and all models $\mathrm{p}<0.01$.

AIC, Akaike's Information Criterion; AUC, area under the curve; CV, coefficient of variance; ROC, receiver operating characteristics.

In Sweden, there is a unique possibility to use register-based data instead of reported data for research purposes, which we could benefit from. We collected individual factors from different data sources to assess the contribution of socioeconomic status, geographical factors, multimorbidity, age, sex and type of primary care to active listing in primary care. To the best of our knowledge, this has not been done before.

Socioeconomic status and geographical factors affect morbidity and trust; therefore, we expected them to affect active listing. We found them to have significant associations with active listing in primary care, but multimorbidity, age, geographical location and primary care explained more than socioeconomic status and distance to healthcare. We also found unexplained differences in the associations between active listing and our explanatory factors according to geographic location.

We found that municipality was the geographical factor that contributed most to the models when tested. To analyse differences in active listing among municipalities was not within the aim of this paper, but we show the complexity by comparing the municipalities with hospitals, also the extremes regarding active listing. Several factors act differently comparing these subpopulations. The models also had difficulties handling type of primary care practice, due to the importance of geographical location. In municipality A, private practices were established before the listing system, with patient lists of only actively listed. On the other hand, private practices in municipality $\mathrm{C}$ were just established; hence, with very few patients listed. To analyse these differences further, our data on local settings and local healthcare were not sufficient.

The relationship between patients and primary care practices was underestimated using active listing, since passive listing at the practice of choice would be sufficient to maintain the relationship. Most actively listed choose to stay listed at the nearest primary care practice.
We anticipate that some were contented with the passive choice made for them and a patient-professional relationship that was not protected. Whether patients act to protect this relationship or not could be influenced by other circumstances such as factors related to social capital and local healthcare.

Data on exact geographical location (GIS data) or active listing at individual primary care practices or GPs were not available. We could group primary care practices by ownership, also including differences in size, team competence, number of listed patients and time since establishment. It was within the aim of this paper to investigate if we could find differences in active listing according to factors in primary care and not how these factors worked. The use of statistical methods allows us to study associations, not causality. To investigate the differences between municipalities, we would need more data on differences between local societies and local healthcares. We also would use mixed methods to investigate how these local factors were perceived by patients and primary care practices.

In Sweden, listing was introduced in primary care to empower patients and to introduce market models by allowing the population to choose primary care provider. Since county councils regulate and organise local healthcare, there is no national primary care system. The County of Blekinge in 2007 provided us with a listing system comparable to contemporary Swedish primary care, as well as the legislation in $2010 .{ }^{14}$ Swedish primary care is known to be weak compared with most European primary care. ${ }^{22-24}$ Generalisation of our findings depends on analyses of strength of primary care and on similarities between healthcare organisations and listing systems. Then our findings are generalisable to other primary care systems allowing patients to choose primary care practice across practice boundaries. 
Table 3 Multivariate model tests: associations between active listing in primary care, socioeconomic status and geographical factors, adjusting for sex and age

\begin{tabular}{|c|c|c|c|c|c|}
\hline \multirow[b]{2}{*}{ Multivariate models, model tests } & \multicolumn{2}{|c|}{ Area under ROC curve } & \multirow{2}{*}{$\begin{array}{l}\text { CV } \\
\% \\
\end{array}$} & \multirow[b]{2}{*}{ AIC } & \multirow[b]{2}{*}{ LR test } \\
\hline & AUC & $(95 \% \mathrm{Cl})$ & & & \\
\hline Age and sex & 0.679 & (0.676 to 0.682$)$ & 20.1 & 143382 & \\
\hline Adjusted for age and sex & & & & & 0 \\
\hline Individual income & 0.685 & (0.682 to 0.688$)$ & 20.6 & 142779 & 552 \\
\hline Educational level & 0.686 & (0.683 to 0.689$)$ & 20.8 & 142615 & 715 \\
\hline Distance primary care & 0.681 & (0.678 to 0.684$)$ & 20.2 & 143235 & 99 \\
\hline Distance hospital & 0.685 & (0.682 to 0.688$)$ & 20.6 & 142833 & 502 \\
\hline Municipality & 0.740 & (0.737 to 0.743$)$ & 26.9 & 134599 & 8831 \\
\hline Multimorbidity level & 0.732 & (0.729 to 0.735$)$ & 26.0 & 135902 & 7432 \\
\hline Practice type & 0.687 & (0.684 to 0.690$)$ & 21.0 & 142320 & 1006 \\
\hline Adjusted for multimorbidity, age and sex & & & & & 0 \\
\hline Individual income & 0.734 & (0.731 to 0.736$)$ & 26.2 & 135586 & 322 \\
\hline Educational level & 0.735 & (0.732 to 0.737 ) & 26.4 & 135364 & 543 \\
\hline Distance primary care & 0.732 & (0.729 to 0.735$)$ & 26.1 & 135805 & 106 \\
\hline Distance hospital & 0.736 & (0.733 to 0.739 ) & 26.4 & 135258 & 654 \\
\hline Municipality & 0.784 & (0.781 to 0.787 ) & 32.2 & 125689 & 10221 \\
\hline Practice type & 0.747 & (0.744 to 0.750$)$ & 27.7 & 133429 & 2475 \\
\hline $\begin{array}{l}\text { Adjusted for multimorbidity, age, sex and } \\
\text { practice type }\end{array}$ & & & & & 0 \\
\hline Individual income & 0.749 & (0.746 to 0.751$)$ & 27.9 & 133130 & 305 \\
\hline Educational level & 0.749 & (0.747 to 0.752 ) & 28.1 & 132926 & 508 \\
\hline Distance primary care & 0.747 & (0.744 to 0.750$)$ & 27.8 & 133350 & 89 \\
\hline Distance hospital & 0.750 & (0.748 to 0.753$)$ & 28.1 & 132875 & 564 \\
\hline Municipality & 0.788 & (0.785 to 0.790$)$ & 32.7 & 124801 & 8636 \\
\hline $\begin{array}{l}\text { Adjusted for municipality, multimorbidity, age, } \\
\text { sex and practice type }\end{array}$ & & & & & 0 \\
\hline Individual income & 0.789 & (0.787 to 0.792$)$ & 32.9 & 124448 & 359 \\
\hline Educational level & 0.789 & (0.786 to 0.792$)$ & 32.8 & 124577 & 230 \\
\hline Distance primary care & 0.789 & (0.786 to 0.791 ) & 32.8 & 124688 & 123 \\
\hline Distance hospital & 0.789 & (0.786 to 0.792 ) & 32.8 & 124621 & 190 \\
\hline
\end{tabular}

Blekinge 2007, aged $>15$ years with no missing data $(n=123168)$.

AIC, Akaike's Information Criterion; AUC, area under the curve; CV, coefficient of variance; LR test, likelihood ratio test; ROC, receiver operating characteristics; $\mathrm{n}, 123168$.

\section{Comparison with existing literature}

Other Swedish surveys have investigated reported choice of primary care provider. Glenngard et al reported variance according to age, municipality and occupation, but not self-reported health status, sex or education. ${ }^{25}$ In a previous paper, we found that more consultations, higher multimorbidity level, older age and female gender were positively associated with active listing in primary care. ${ }^{26}$ Here we combined these factors with socioeconomic status, type of primary care practice and geographical factors, and we found that multimorbidity level, age and geographical location contributed most to active listing and that type of primary care practice contributes more than socioeconomic status and distances to healthcare.
In 2012/2013, general practices in four UK National Health Service primary care trusts piloted a scheme allowing patients living outside practice boundaries to enlist as out-of-area patients (active listing). A pilot study using mixed methods investigated patients' experiences of their choice of practice. A patient with a choice across practice boundaries was younger and more likely to be working compared with other patients at the same practices. Common reasons to become an out-of-area patient were convenience, not wanting to change practice after moving house, newcomers to the area and dissatisfaction with previous practice. ${ }^{27}$ We found that, after some years allowing all to list actively, higher multimorbidity level and older age were associated with active listing. We also 


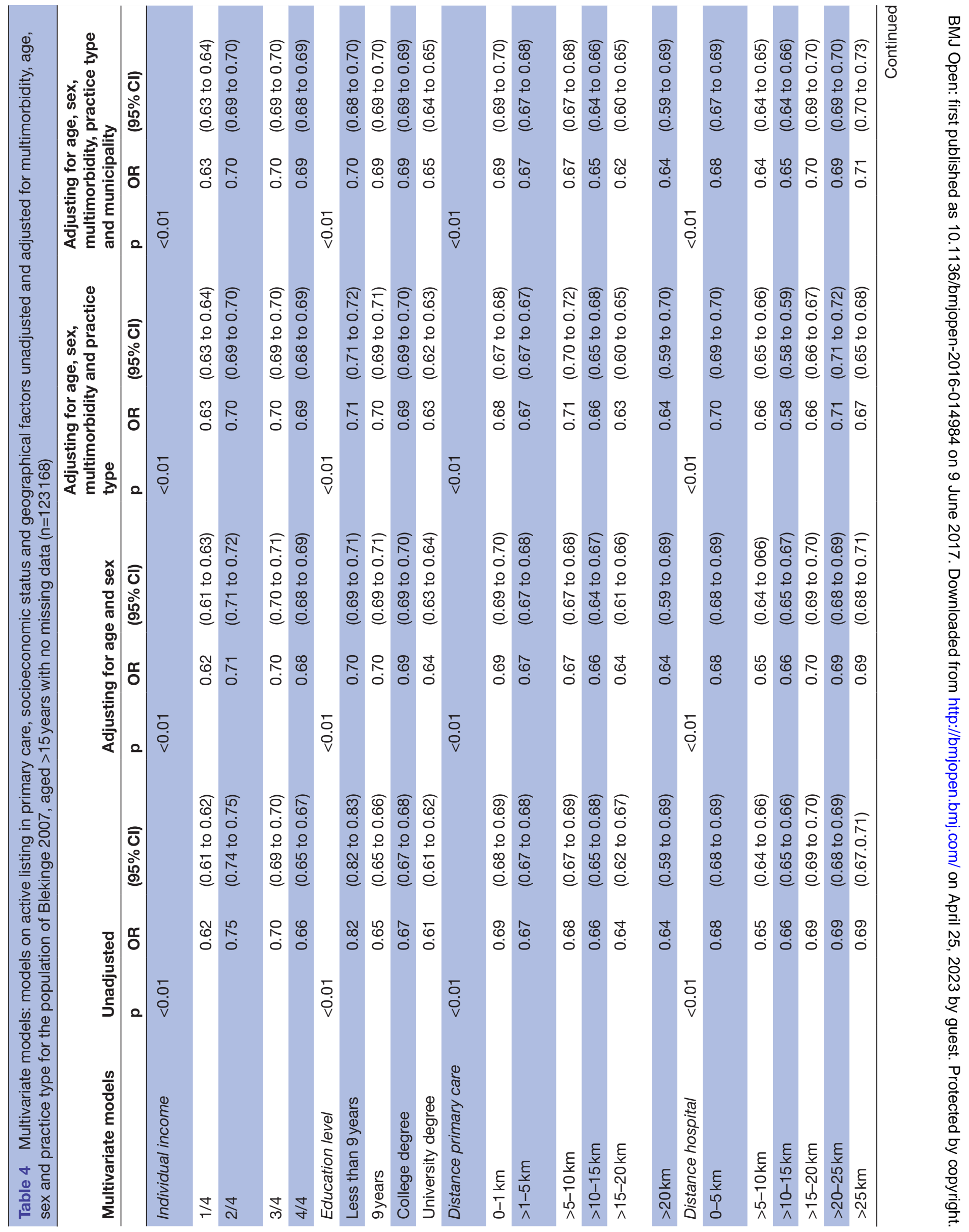




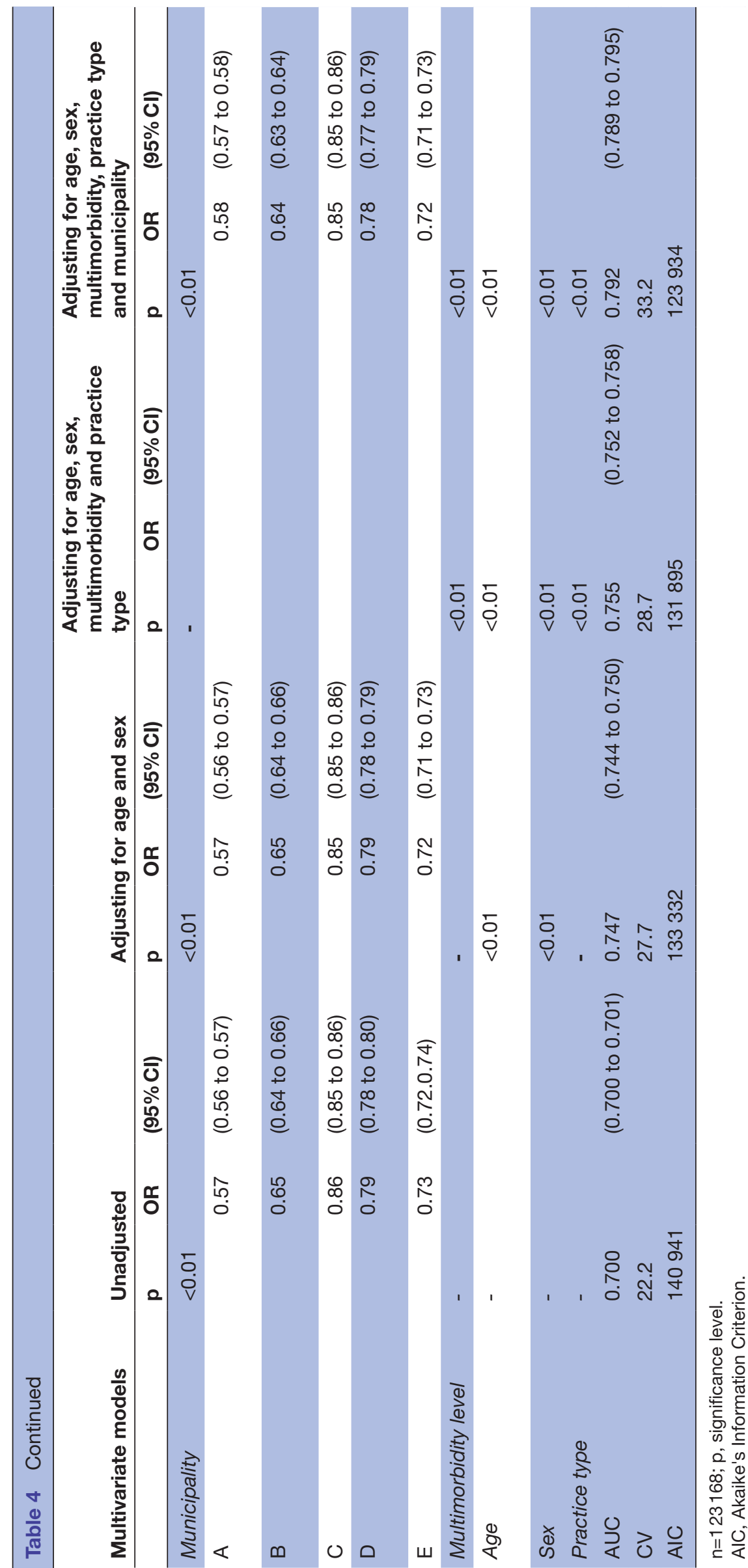

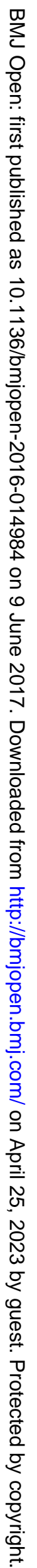


Table 5 Multivariate logistic regression models: associations between active listing in primary care, socioeconomic status and geographical factors, adjusting for multimorbidity, type of primary care practice, sex and age

\begin{tabular}{|c|c|c|c|c|c|c|}
\hline \multirow[t]{2}{*}{ Logistic models } & \multicolumn{2}{|c|}{$\begin{array}{l}\text { Including all factors, } \\
\text { municipality A ( } n=49 \text { 931) }\end{array}$} & \multicolumn{2}{|c|}{$\begin{array}{l}\text { Including all factors, } \\
\text { municipality } C(n=20020)\end{array}$} & \multicolumn{2}{|c|}{$\begin{array}{l}\text { Including all factors, population of } \\
\text { Blekinge }(n=123168)\end{array}$} \\
\hline & OR & (95\% Cl) & OR & (95\% Cl) & OR & (95\% Cl) \\
\hline \multicolumn{7}{|l|}{ Individual income } \\
\hline $1 / 4$ & 1.00 & & 1.00 & & 1.00 & \\
\hline $2 / 4$ & $1.45^{\star \star}$ & (1.36 to 1.55$)$ & $1.54^{\star \star}$ & (1.34 to 1.75$)$ & $1.45^{\star \star}$ & (1.39 to 1.52$)$ \\
\hline $3 / 4$ & $1.37^{\star \star}$ & (1.28 to 1.46$)$ & $1.87^{\star \star}$ & (1.66 to 2.11 ) & $1.49^{\star \star}$ & (1.42 to 1.55$)$ \\
\hline $4 / 4$ & $1.22^{* *}$ & (1.14 to 1.31$)$ & $1.71^{\star *}$ & (1.51 to 1.94 ) & $1.40^{\star *}$ & (1.33 to 1.46$)$ \\
\hline \multicolumn{7}{|l|}{ Education level } \\
\hline Less than 9 years & 1.00 & & 1.00 & & 1.00 & \\
\hline 9 years & 0.90 & (0.81 to 1.00$)$ & 1.08 & (0.88 to 1.33 ) & 0.97 & (0.91 to 1.04$)$ \\
\hline College degree & 0.94 & (0.87 to 1.01$)$ & 0.95 & (0.81 to 1.12 ) & 0.96 & (0.91 to 1.01$)$ \\
\hline University degree & $0.77^{\star \star}$ & (0.71 to 0.84$)$ & $0.66^{\star \star}$ & (0.56 to 0.79 ) & $0.74^{\star *}$ & (0.70 to 0.78$)$ \\
\hline \multicolumn{7}{|l|}{ Distance primary care } \\
\hline $0-1 \mathrm{~km}$ & 1.00 & & 1.00 & & 1.00 & \\
\hline$>1-5 \mathrm{~km}$ & $0.83^{\star *}$ & (0.79 to 0.88 ) & 1.08 & (0.98 to 1.18 ) & $0.90^{* *}$ & (0.87 to 0.93 ) \\
\hline$>5-10 \mathrm{~km}$ & $0.81^{\star \star}$ & (0.74 to 0.87 ) & $2.44^{\star *}$ & (2.07 to 2.87 ) & $0.90^{\star *}$ & (0.86 to 0.94$)$ \\
\hline$>10-15 \mathrm{~km}$ & $0.73^{\star \star}$ & (0.63 to 0.84 ) & 1.45 & (0.98 to 2.13 ) & $0.79^{* *}$ & (0.72 to 0.85$)$ \\
\hline$>15-20 \mathrm{~km}$ & $0.65^{\star \star}$ & (0.50 to 0.85$)$ & 0.73 & (0.38 to 1.39$)$ & $0.68^{\star \star}$ & (0.59 to 0.78$)$ \\
\hline$>20 \mathrm{~km}$ & 0.51 & (0.17 to 1.56$)$ & - & & $0.74^{\star *}$ & (0.56 to 0.98$)$ \\
\hline \multicolumn{7}{|l|}{ Distance hospital } \\
\hline $0-5 \mathrm{~km}$ & 1.00 & & 1.00 & & 1.00 & \\
\hline$>5-10 \mathrm{~km}$ & $0.80^{\star \star}$ & (0.76 to 0.86$)$ & $0.45^{\star \star}$ & (0.40 to 0.51$)$ & $0.81^{\star \star}$ & (0.77 to 0.85 ) \\
\hline$>10-15 \mathrm{~km}$ & $0.89^{* *}$ & (0.83 to 0.96$)$ & $0.47^{\star *}$ & (0.37 to 0.60$)$ & $0.83^{\star *}$ & (0.78 to 0.88$)$ \\
\hline$>15-20 \mathrm{~km}$ & 1.04 & (0.95 to 1.14$)$ & 0.78 & (0.48 to 1.27$)$ & $1.10^{\star *}$ & (1.03 to 1.17 ) \\
\hline$>20-25 \mathrm{~km}$ & 0.89 & (0.77 to 1.04$)$ & $0.38^{\star}$ & (0.17 to 0.85$)$ & $1.09^{* *}$ & (1.02 to 1.16$)$ \\
\hline$>25 \mathrm{~km}$ & $0.72^{\star \star}$ & (0.58 to 0.89 ) & - & & $1.23^{\star \star}$ & (1.10 to 1.38$)$ \\
\hline Municipality & - & & - & & & \\
\hline A & & & & & 1.00 & \\
\hline B & & & & & $1.35^{\star *}$ & (1.28 to 1.43$)$ \\
\hline C & & & & & $5.62^{\star \star}$ & (5.37 to 5.87 ) \\
\hline D & & & & & $3.21^{\star *}$ & (3.01 to 3.43 ) \\
\hline E & & & & & $2.12^{\star \star}$ & (1.97 to 2.28 ) \\
\hline \multicolumn{7}{|l|}{ Multimorbidity level } \\
\hline RUB 0 & 1.00 & & 1.00 & & 1.00 & \\
\hline RUB 1 & $3.14^{\star \star}$ & (2.96 to 3.34 ) & $3.97^{\star *}$ & (3.50 to 4.50$)$ & $2.70^{\star *}$ & (2.58 to 2.81 ) \\
\hline RUB 2 & $4.00^{\star *}$ & (3.79 to 4.22 ) & $4.42^{\star *}$ & (3.97 to 4.93 ) & $3.29^{\star *}$ & (3.17 to 3.42 ) \\
\hline RUB 3 & $5.89^{\star \star}$ & (5.57 to 6.22 ) & $8.16^{\star \star}$ & (7.14 to 9.33 ) & $5.08^{\star *}$ & (4.88 to 5.29$)$ \\
\hline RUB 4 & $8.95^{\star \star}$ & (7.59 to 10.56$)$ & $6.72^{\star \star}$ & (4.63 to 9.77 ) & $6.99^{\star \star}$ & (6.18 to 7.89 ) \\
\hline RUB 5 & $10.40^{\star *}$ & (6.72 to 16.10$)$ & $7.17^{\star *}$ & (2.23 to 23.04 ) & $9.27^{\star *}$ & (6.60 to 13.02$)$ \\
\hline \multicolumn{7}{|l|}{ Age } \\
\hline 16-19years & 1.00 & & 1.00 & & 1.00 & \\
\hline 20-39 years & 1.05 & (0.93 to 1.18$)$ & $0.54^{\star \star}$ & (0.44 to 0.66$)$ & $0.74^{\star \star}$ & (0.68 to 0.79 ) \\
\hline 40-59years & $1.60^{\star *}$ & (1.42 to 1.81$)$ & 1.01 & (0.82 to 1.25$)$ & $1.24^{\star *}$ & (1.15 to 1.34$)$ \\
\hline $60-79$ years & $3.25^{\star \star}$ & (2.87 to 3.69 ) & $1.81^{\star *}$ & (1.43 to 2.29$)$ & $2.44^{\star \star}$ & (2.25 to 2.64$)$ \\
\hline
\end{tabular}


Table 5 Continued

\begin{tabular}{|c|c|c|c|c|c|c|}
\hline \multirow[t]{2}{*}{ Logistic models } & \multicolumn{2}{|c|}{$\begin{array}{l}\text { Including all factors, } \\
\text { municipality } A \text { ( } n=49 \text { 931) }\end{array}$} & \multicolumn{2}{|c|}{$\begin{array}{l}\text { Including all factors, } \\
\text { municipality } C(n=20020)\end{array}$} & \multicolumn{2}{|c|}{$\begin{array}{l}\text { Including all factors, population of } \\
\text { Blekinge }(n=123168)\end{array}$} \\
\hline & OR & (95\% Cl) & OR & (95\% Cl) & OR & (95\% Cl) \\
\hline \multicolumn{7}{|l|}{ Sex } \\
\hline Women & 1.00 & & 1.00 & & 1.00 & \\
\hline \multicolumn{7}{|l|}{ Practice type } \\
\hline Private & 1.00 & & - & & 1.00 & \\
\hline Public & $0.01^{* *}$ & (0.00 to 0.01$)$ & - & & $0.53^{\star *}$ & (0.51 to 0.55$)$ \\
\hline
\end{tabular}

Separate models for the subpopulations of municipality A ( $n=49$ 931) and C ( $n=20020)$, and Blekinge $(n=123168) 2007$, aged $>15$ years with no missing data.

${ }^{*} \mathrm{p}<0.01 ;{ }^{* *} \mathrm{p}<0.05$.

showed that factors in local society (geographical location and type of primary care practice) played a role in patients' choice of practice, while distances to healthcare, education and income were less important to active choice.

In a Scottish study, it was found that more than half of people with multimorbidity were $<65$ years old and that there was an excess of multimorbidity in the most deprived areas. ${ }^{28} \mathrm{~A}$ retrospective cohort study in England showed that multimorbidity, age and deprivation were strongly related and that people with multimorbidity had higher consultation rates and less continuity of care compared with people without multimorbidity. ${ }^{29}$ We confirmed the associations previously found between multimorbidity, age and municipality and their associations with active listing. We found no significant correlation between municipality and multimorbidity level. In accordance with the established influence of socioeconomic and geographical factors on both morbidity and trust, we expected that including such factors would contribute to variance and explanatory power of active listing. We found that most of the contribution of socioeconomic status and geographical factors was lost, when we adjusted for multimorbidity, age and sex, except for geographical location. The remaining association was still statistically significant and showed a positive association between active listing and higher income, shorter education, short distance to primary care or long distance to a hospital.

\section{Conclusions and perspectives}

Multimorbidity, age, geographical location and type of primary care practice are more important to active listing in primary care than socioeconomic status and distance to healthcare.

Higher income, shorter education and short distance to primary care or long distance to hospital still have some importance to active listing in primary care.

Influence of socioeconomic status on health, and vice versa, partly could explain the unexpected weak associations between socioeconomic status and active listing in adjusted models. The stronger association between geographical location, rather than distances to healthcare, and active listing implicates that data on geographical location (GIS data) should be used to investigate the influence of geographical factors to the strength of the relation between patients and practices in primary care.

The associations between active listing, geographical location and primary care implicate that factors within local societies and local healthcare affect active listing. The cause and implications of these differences in the relation between patients and primary care need further research, as well as the use of mixed methods to include how studied factors are perceived.

Acknowledgements We are indebted to Lise Keller Stark for her expertise and invaluable advice in proofreading the manuscript.

Contributors In accordance with the Vancouver Protocol, KR, PM and AH all have contributed to the design of this study, interpretation of data, drafting and revising the article and final approval of the version to be published. KR and AH acquisited data and performed the statistical analyses.

Competing interests None declared.

Ethics approval EPN Lund, Sweden.

Provenance and peer review Not commissioned; externally peer reviewed.

Open Access This is an Open Access article distributed in accordance with the Creative Commons Attribution Non Commercial (CC BY-NC 4.0) license, which permits others to distribute, remix, adapt, build upon this work non-commercially, and license their derivative works on different terms, provided the original work is properly cited and the use is non-commercial. See: http://creativecommons.org/ licenses/by-nc/4.0/

(C) Article author(s) (or their employer(s) unless otherwise stated in the text of the article) 2017. All rights reserved. No commercial use is permitted unless otherwise expressly granted.

\section{REFERENCES}

1. Starfield B, Shi L, Macinko J. Contribution of primary care to health systems and health. Milbank Q 2005;83:457-502.

2. Starfield B, Lemke KW, Bernhardt T, et al. Comorbidity: implications for the importance of primary care in 'case' management. Ann Fam Med 2003;1:8-14.

3. Lindström M, Axén E, Lindström $C$, et al. Social capital and administrative contextual determinants of lack of access to a regular 
doctor: a multilevel analysis in southern Sweden. Health Policy 2006;79:153-64.

4. Vedsted P, Heje HN. Association between patients' recommendation of their GP and their evaluation of the GP. Scand J Prim Health Care 2008;26:228-34.

5. Heje HN, Vedsted P, Sokolowski I, et al. Patient characteristics associated with differences in patients' evaluation of their general practitioner. BMC Health Serv Res 2008;8:178.

6. Rosén P, Anell A, Hjortsberg C. Patient views on choice and participation in primary health care. Health Policy 2001;55:121-8.

7. Arora R, Singer J, Arora A. Influence of key variables on the patients' choice of a physician. Qual Manag Health Care 2004;13:166-73.

8. Hastie R, Dawes RM. Rational choice in an uncertain world: the psychology of judgement and decision making. Thousand Oaks, Calif.; London: Sage Publications, 2001.

9. Macinko J, Starfield B. The utility of social capital in research on health determinants. Milbank Q 2001;79:387-427.

10. Lindström M. Social capital and lack of belief in the possibility to influence one's own health: a population-based study. Scand $J$ Public Health 2006;34:69-75.

11. Mohseni M, Lindstrom M, . Social capital, trust in the health-care system and self-rated health: the role of access to health care in a population-based study. Soc Sci Med 2007:64:1373-83.

12. Violan C, Foguet-Boreu Q, Flores-Mateo G, et al. Prevalence, determinants and patterns of multimorbidity in primary care: a systematic review of observational studies. PLoS One 2014;9:e102149.

13. France EF, Wyke S, Gunn JM, et al. Multimorbidity in primary care: a systematic review of prospective cohort studies. $\mathrm{Br} J$ Gen Pract 2012:62:297-307.

14. Anell $\mathrm{A}$, Glenngård $\mathrm{AH}$, Merkur S. Sweden health system review. Health Syst Transit 2012;14:1-159.

15. Ahgren $B$, Nordgren $L$. Is choice of care compatible with integrated health care? An exploratory study in Sweden. Int J Health Plann Manage 2012:27:162-172.

16. Government Offices of Sweden. Vårdval i primärvården. Prop 2008. available at http://www.regeringen.se/sb/d/108/a/117176 (/09:74 [Government bill on a national listing system in Swedish Primary Care] .accessed 3 February 2016).
17. Ahgren B. Competition and integration in Swedish health care. Health Policy 2010:96:91-7.

18. SCB. Befolkningens medelålder efter region och kön. År 1998 - 2014 [Epidemiologic data in 2007available at From Statistics Sweden] .http://www.statistikdatabasen.scb.se/pxweb/sv/ssd/START BE BE0101_BE0101B/?rxid=d0708db6-5d32-49b3-b0a8$075 \mathrm{c} 87 \mathrm{a} 7 \mathrm{c} 302$

19. Sweden Statistics available at http://www.scb.se

20. Starfield B, Weiner J, Mumford L, et al. Ambulatory care groups: a categorization of diagnoses for research and management. Health Serv Res 1991;1:53-74.

21. Zielinski $A$, Kronogård $M$, Lenhoff $H$, et al. Validation of $A C G$ casemix for equitable resource allocation in Swedish primary health care. BMC Public Health 2009;9:347.

22. Kringos DS, Boerma WG, Bourgueil $Y$, et al. The european primary care monitor: structure, process and outcome indicators. BMC Fam Pract 2010;11:81.

23. Kringos DS, Boerma W, van der Zee J, et al. Europe's strong primary care systems are linked to better population health but also to higher health spending. Health Aff 2013:32:686-94.

24. Haggerty JL, Lévesque JF, Hogg W, et al. The strength of primary care systems. BMJ 2013;346:f3777.

25. Glenngård $A H$, Anell $A$, Beckman $A$. Choice of primary care provider: results from a population survey in three Swedish counties. Health Policy 2011;103:31-7.

26. Ranstad K, Midlöv P, Halling A. Importance of healthcare utilization and multimorbidity level in choosing a primary care provider in Sweden. Scand J Prim Health Care 2014;32:99-105.

27. Tan S, Erens B, Wright M, et al. Patients' experiences of the choice of GP practice pilot, 2012/2013: a mixed methods evaluation. BMJ Open 2015;5:e006090

28. Barnett K, Mercer SW, Norbury M, et al. Epidemiology of multimorbidity and implications for health care, research, and medical education: a cross-sectional study. Lancet 2012:380:37-43.

29. Salisbury C, Johnson L, Purdy S, et al. Epidemiology and impact of multimorbidity in primary care: a retrospective cohort study. $\mathrm{Br} J$ Gen Pract 2011:61:12-21. 